\title{
Design and Fabrication of a Motorized Prototype Tricycle for the Disable Persons
}

\author{
Abdulkadir Baba Hassan \\ Department of Mechanical Engineering, Federal University of Technology, Minna, Niger State, Nigeria
}

\begin{abstract}
This project design is embodied on a motorized tricycle for disabled Persons. The tricycle was specifically designed to suit wheelchair occupants of healthy Upper torso with pelvic to foot restraint. It is also designed to suit a commonly available Wheel chair. The level of relationship between the disabled people in the society has highly being jeopardized; therefore this project was designed to correct the difficulties in mobility of the wheelchair users. The main aim of the project design is to ease mobility for the physically challenged and also provide adequate comfort they desire. Existing tricycles for the disables requires the disabled person to dismount from the wheelchair onto the tricycle. The motorized tricycle in this project is designed to overcome this problem by allowing the disabled person to wheel up or down his wheelchair onto or down the tricycle. This is achieved using a specially designed platform that allows the wheel chair to be wheeled up or down. The prototype of this tricycle has been fabricated. The anthropometrics data that need to be considered in the design of the platform and frame of the tricycle have been taken into consideration at the design stage of the tricycle.
\end{abstract}

Keywords: Motorise, Prototype, Tricycle, and Wheel chair.

\section{Introduction}

In the time past before the invention of vehicles, men traveled on foot, and horse drawn carriages (either donkeys, dogs of the wolf breed, and camels) were used. Transportation being a major means of communication was very essential for the peaceful coexistence of the human race and empire depended on it for mobility.

Mobility is an important requirement in providing motordisabled adults opportunities for independent living and working. There have been many published examples of the disabled contributing to the workforce not just in service sector but also in industrial sector (Kochan, 1996, and Burke 1999).

A successful effort to include motor-disabled employees into the workforce not only involved adjustments to the workplace and work environment but also the issues of facilitating the transportation of these employees to and from work. Many specially designed vehicles have been built for this purpose.

This project aims to design and fabricate a prototype tricycle to improve mobility of the motor-disabled with healthy upper torso but pelvic to foot restraint. Tricycle became highly acceptable, in Nigeria for instance, where disabled and wheelchair users are less privileged they in their own way put in place things for the pleasure of life and its environment. Due to the fact that a disabled person may not generate the same power to its counterpart. This project is aim at providing a motorized tricycle for the disabled (physically challenged) wheel chair users. The physical anthropometrics data of the disable person is used to determine the relative component of the tricycle that will abate the effect of the biomechanical stresses that arises due to excessive postural deviation factor.

A tricycle that is for the wheel chair users, which has an engine mounted to a frame and platform for the movement in and out the frame. It also consists of a hand brake, hand

gear lever, a footrest on the platform of the tricycle.

\section{Design Considerations}

In building the prototype tricycle many design factors need to be considered. However this paper will only focus on the anthropometrics considerations in the design of the frame, handle, platform, ramp and footrest of the tricycle. Refer to figure 1 below.

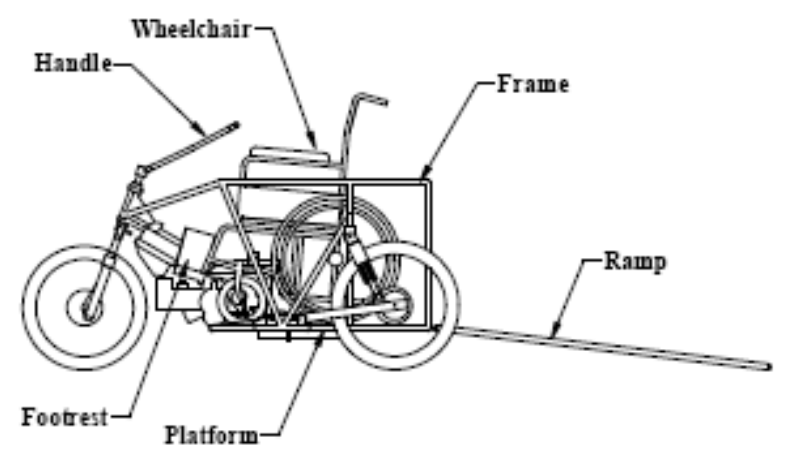

Figure 1 Schematic design of the tricycle 


\section{Frame and Platform Design}

The frame basically consists of handrails on both sides of the platform. The function of the handrail is to assist the handicap in moving and adjusting wheelchair position on the tricycle. The handrail also acts as a safety fence. The main factors that need to be considered are:

i) Width,

ii) Height and

iii) Diameter of the gripping of the handrail.

Berezovsky, et-al(1988).

\section{Ramp Design}

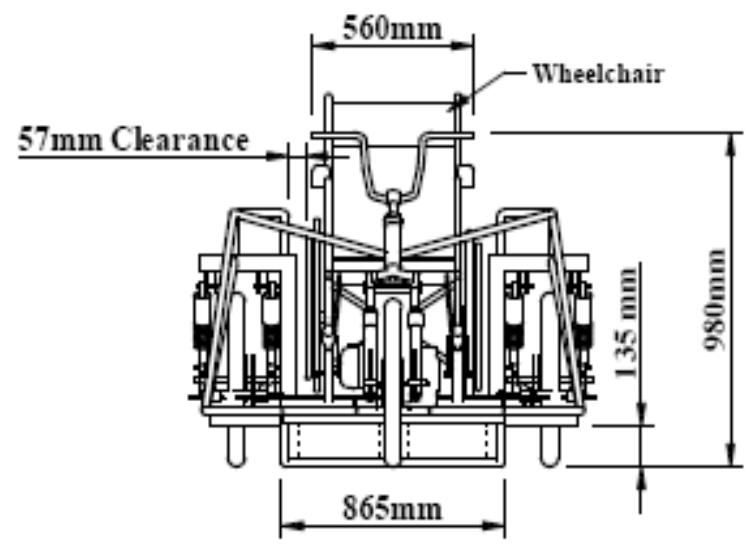

Fig.2. Front view of the tricycle

Determination of distance between backrest of wheel and the kick starter (crank position) of the tricycle The distance denoted by $\mathrm{Z}_{\mathrm{a}}$

$\mathrm{Z}_{\mathrm{a}}=\mathrm{L}_{7}+\mathrm{L}_{8} \quad$ (1)

$\mathrm{Z}_{\mathrm{a}}=$ Distance from back rest of the wheel chair to the crank ones.

\section{Determination of height of crank axis above the floor}

$\mathrm{H}_{\mathrm{a}}=\mathrm{Y}_{\mathrm{a}}+\mathrm{L}_{4}+\mathrm{L}_{1}$

where $\mathrm{Y}_{\mathrm{a}} \longrightarrow$ Distance between the floor to the platform. $\mathrm{Y}_{\mathrm{a}}$ is also the platform clearance.

$\mathrm{L}_{1}$ is defense between the wheel chair seat and crank. Krovt et.al (1994).

Determination of center between rear and front wheel $\mathrm{C}=\mathrm{L}_{3}+\mathrm{pq}^{1}+\mathrm{K}+\mathrm{D}_{\mathrm{R}}$ 2 wheel

$\mathrm{D}_{\mathrm{R}}-\quad$ diameter of front wheel

$\mathrm{K}$ - Clearance (distance) between frame and front wheel.

Strain energy stored in the body when the wheelchair is gradually wheeled into the frame

$\mathrm{P}=$ Load gradually applied

$\mathrm{A}=$ cross-sectional area of the bar

$1=$ length of bar

$\mathrm{E}=$ modulus of elasticity of the bar material

$\delta=$ deformation of the bar due to load
In the case of ramps and landings with drop-offs, it is recommended that it should have projecting surfaces to prevent from slipping off.

\section{Footrest Design}

A special footrest has to be design apart from wheelchair footrest to facilitate the tricycle user's comfort.

\section{The Handle}

It would be desirable to allow the elbows to rest on the armrest of the wheelchair. Thus fitting trials is crucial here in determining the most comfortable posture and dimensions. Refer Figure 2. if load is $\mathrm{P} / 2$

Workdone $=$ Force $\mathrm{x}$ distance

$$
\begin{aligned}
& =\text { average load } \times \text { deformation } \\
& =(\mathrm{P} / 2) \times \delta 1=(\mathrm{P} / 2)(\varepsilon .1) \text { and } \mathrm{P}=\sigma \mathrm{A} \\
& =(1 / 2) . \sigma . \varepsilon \mathrm{A} .1 \\
& =(1 / 2) \times(\text { stress } \times \text { strain } \times \text { volume }) \\
& =(1 / 2) \times \sigma \times \sigma / \mathrm{E} \times \mathrm{Al} \\
& =(1 / 2) \times\left(\sigma^{2} / \mathrm{E}\right) \times \mathrm{Al} \\
& =\sigma^{2} \mathrm{~V} / 2 \mathrm{E}
\end{aligned}
$$

Since energy stored is equal to workdone,

$$
\mathrm{U}=\sigma^{2} / 2
$$

The needed joint in the frame attached to the tricycle Strength of a fillet weld is given by the relation $\mathrm{P}=1 . \mathrm{t} . \sigma=\mathrm{A} . \sigma$

1 is the effective length of the weld $t$ is thread thickness $\sigma$ is permissible stress in the fillet weld.

Power required wheeling the tricycle From Resheston calculation (1985) that: Power, $\mathrm{P}=\mathrm{Wv} / 3.73$ and $\mathrm{W}=$ weight of tricycle $(\mathrm{N}$ or $\mathrm{Kg})$

$\mathrm{v}=$ minimum linear speed of engine $(\mathrm{m} / \mathrm{s})$

if $\omega$ is angular velocity $\omega=2 \pi / T=2 \Pi n / 60$

$\mathrm{P}=$ Workdone/Time Taken

$\mathrm{P}=\mathrm{T} . \omega=\mathrm{T} .(2 \Pi \mathrm{N} / 60)\left(\omega^{2} \mathrm{~Hz}\right)$

and $\mathrm{T}$ is torque transmitted when $\mathrm{N}$ is the speed in rpm 
from $\omega=2 \Pi \mathrm{N} / 60 ; \mathrm{N}=\omega .60 / 2 \pi(\mathrm{rpm})$

to obtain the driven torque $\mathrm{T} ; \mathrm{T}=\mathrm{P} / \omega$

\section{Testing of Machine}

Materials used basically in mechanical design and construction seldom requires various test and balance in both its static and dynamic as well as its physical and mechanical properties to enable their state standard and efficient use in load bearing with or without load application.

Mechanical properties describe the behaviors of structural material subjected to mechanical forces when in operation. During the test, some conditions were ascertained. These factors include:

- The nature of applied load

- The maximum speed applied

- The duration of the applied load

- The environmental conditions under which the load was applied

- And the road surface conditions

As a result of these following factors, static test has confirmed the tricycle stability, properly aligned, since all the extra weights was installed as low as possible to the centre of gravity of the tricycle.
Dynamic test conducted confirmed also the stability, easy maneuvering, no overheating, normal fuel consumption, the effectiveness of the braking system, the approximate distance covered per kilometer hour.

\section{Technical descriptions}

The tricycle frame is made of sheet for the platform and the ramp and round pipe of 1 inch. It is to be a compartment where the wheel chair will be wheeled into. The seat, back support, armrest all of the standard size wheel chair.

The wheels are of equal sizes for the rear, with new inflated tyres. The front brake lever is mounted on the right handle bar, while the rear brake lever is operated at the right side of the rider. This is in order to connect with the throttle, and as soon as he releases the throttle, he applies the brake to order to bring it to rest.

The front wheel is steered and the drive train is mounted on the driven side, where the sprocket is connected to, because the shaft was eliminated. The front and the other rear wheels are idle one.

It is also attached and connected to a battery for the hand starting / ken staring mechanisms. The gear lever is connected to a leverage which enables easy access to the controlling of its mechanism by the disable person without stress.

TABLE 1. MACHINE MAIN PARAMETERS AND SPECIFICATIONS

\begin{tabular}{|l|l|l|}
\hline S/N & \multicolumn{1}{|c|}{ ITEMS } & SPECIFICATIONS \\
\hline 1 & Length of tricycle & $1267 \mathrm{~mm}$ \\
\hline 2 & Width of tricycle & $925 \mathrm{~mm}$ \\
\hline 3 & Height of tricycle & $980 \mathrm{~mm}$ \\
\hline 4 & Wheel chair seat level to the platform & $335 \mathrm{~mm}$ \\
\hline 5 & Ground clearance & $135 \mathrm{~mm}$ \\
\hline 6 & Highest speed & $50 \mathrm{Km} / \mathrm{hr}$ \\
\hline 7 & Dead weight & $70 \mathrm{Kg}$ \\
\hline 8 & Pay load & $95 \mathrm{Kg}$ \\
\hline 9 & Fuel tank capacity & 4 liters \\
\hline 10 & Engine oil Tank & $1.0 \mathrm{liter}$ \\
\hline 11 & Speed & $\leq 45 \mathrm{Km} / \mathrm{hr}$ \\
\hline 12 & Fuel consumption rate & 1.2 liters/ 75Km \\
\hline 13 & Reserve & 1.0 liter \\
\hline 14 & Starting method & Electric starting \\
\hline 15 & Ignition system & CDI electronic \\
\hline 16 & Spark plug type & C7HSA Japan NGK \\
\hline 17 & Spark plug gap & $0.3 \approx 0.5 \mathrm{~mm}$ \\
\hline 18 & Front tyre size & $2.2 \approx 17 \mathrm{Pr}$ \\
\hline & & \\
\hline
\end{tabular}




\begin{tabular}{|l|l|l|}
\hline 19 & Rear tyre size & $2.2 \approx 17 \mathrm{Pr}$ \\
\hline 20 & Battery & 12 volts $4 \mathrm{AH} / 10 \mathrm{H}$ \\
\hline
\end{tabular}

\section{Conclusion}

In conclusion, we have reported five main design factors in building the prototype tricycle it has been created to suit the wheelchair users and only ADA Standards for the Accessible Design Pt. 36 has been referred as dimension guideline in building the tricycle prototype.

The main parts of the prototype tricycle such as the frame, handle and platform have been fabrication. Fitting trials on a selected group of user should be conducted as field study to establish the suitable static and dynamic anthropometric data that will contribute to the comfort and safety for the users. Further improvement on the tricycle should be carried out for further research project. However, some of the design concept could not really be apprehended to due to design errors and difficulty; the shaft could not be connected between the rear rims.

\section{Recommendation}

It is recommended that in cases of re-modification of the tricycle proper consideration should be taken in Ramp a spring lift should be included to ease the entrance without little assistance of a person acting as guide. The listening channels of the tricycle should be included, to ease the stress of visibility and to enable the disable person use the tricycle at night situations. In addition, the safety of the tricycle should be modify to an improve standard. Moreover, for any imperfect constraint in the frame, provision is available for easy amendment. I also recommend that more attention should be in the ergonomics aspect of the project and the placing of the chain at the middle of the frame beneath the platform in the future.

I will also wish to recommend that, for such project in the future, more work forces should be merged to lessen the ease of the burden.

\section{REFERENCES}

Berezovsky, Y. U., Chernilevsky D., Petrov M., (1988) Machine Design, MIR publisher Moscow. Burke, R.J., (1999), Disability and Women's Work Experiences: An exploratory study, International journal of Sociology and Social policy. 19(12), 21-33.

Kochan, A., 1996, Remploy: disabled and thriving, Assembly Automation, Volume 16, Number 1, pg. $40-41$.

Krovt et.al, 1994, Design of a walking

Wheelchair for the motor disabled, Proceedings of the 4th International Conference on Rehabilitation Robotics, Wilmington D.E., pg. 125 - 130.

Industrial Ergonomics, Volume 17, pg 113 - 121.

Resheston D.N (1985), Machine Design,

MIR Publishers, Moscow. Pg34-65 